\title{
Synthesis and Characterization of the Ground
}

\author{
and Excited States of Tripodal-like
}

\section{Oligothienyl-imidazoles}

João Pina, ${ }^{\dagger}$ J. Sérgio Seixas de Melo, ${ }^{* \dagger}$ Rosa M. F. Batista, ${ }^{+}$Susana P.G. Costa ${ }^{+}$and M. Manuela M. Raposo *t $^{*}$

${ }^{\dagger}$ Departamento de Química da Universidade de Coimbra, Rua Larga, 3004-535 Coimbra, Portugal

* Centro de Química, Universidade do Minho, Campus de Gualtar, 4710-057 Braga, Portugal

* Corresponding authors. Fax: 00351239 827703. E-mail: sseixas@ci.uc.pt; Fax: 00351 253 604382. E-mail: mfox@quimica.uminho.pt.

RUNNING HEAD: Tripodal-like Oligothienyl-imidazole Derivatives 
ABSTRACT: Six new thiophene oligomers, here designated as tripodal-like oligothienyl imidazoles, were synthesized and have been investigated in ethanol solution at room and low temperature. The oligomers bear a common core where two or more thiophenes are linked to one or more imidazole unit which further links through its $\alpha$ position to a different number of incremental thiophene units. The study involves a comprehensive spectral and photophysical investigation where the properties of the singlet and triplet states have been investigated regarding absorption, fluorescence and phosphorescence, transient triplet-triplet absorption together with all relevant quantum yields (fluorescence, $\phi_{\mathrm{F}}$, internal conversion, $\phi_{\mathrm{IC}}$, intersystem crossing, $\phi_{\mathrm{T}}$, and singlet oxygen, $\left.\phi_{\Delta}\right)$ and lifetimes. In addition, DFT quantum chemical calculations were performed to gain a detailed understanding of the molecular geometry and optical properties of the investigated oligomers. From the overall data, the radiative $\left(\mathrm{k}_{\mathrm{F}}\right)$ and radiationless $\left(\mathrm{k}_{\mathrm{NR}}, \mathrm{k}_{\mathrm{IC}}\right.$ and $\mathrm{k}_{\mathrm{ISC}}$ ) rate constants have been determined and it is shown that, in contrast with the parent oligothiophenes, the radiative competes with the radiationless deactivation channels. The results show that, by comparison with the oligothiophene counterparts, there is an augment of the relative contributions of the internal conversion and fluorescence processes relative to the $S_{1} \sim \sim T_{1}$ intersystem crossing. Phosphosphorescence emission was found for the simplest member of the investigated compounds, with a low quantum yield $\left(\phi_{\mathrm{Ph}}=0.009\right)$ and a lifetime of $8 \mu \mathrm{s}$. The data also show that the introduction of a 4,5-dithienyl-imidazole moiety in a bi- or terthiophene oligomer results in, respectively, a 20-fold and a 3-fold increase of the fluorescence quantum yield relative to their oligothiophene counterparts.

KEYWORDS: Oligothiophenes; Imidazoles; Tripodal derivatives; Excited-state; Fluorescence; Triplet-state, DFT

BRIEFS: Six new thiophene oligomers were synthesized for the first time and their photophysical characterization has been investigated in solution at room and low temperature. 


\section{Introduction}

Organic conjugated polymers are nowadays still the focus of intense research investigations in the field of organic electronics, due to their appealing applications such as electroluminescent devices, sensors, lasers and other semiconductor devices. ${ }^{1}$ Organic luminescent compounds, however, still have stability problems and the correlation between structure and fluorescence efficiency is yet far from being satisfactorily understood. While many chromophores have been designed and synthesized, it remains essential to find molecular structures exhibiting high fluorescence and high stability. Thermal and chemical instability of organic materials are considered major factors in the low operation stability under high-temperature conditions. Therefore, approaches for improving the thermal stability of organic molecules, without reducing fluorescence, are needed. ${ }^{2-4}$ In this respect, promising candidates are imidazole derivatives, ${ }^{5-23}$ as well as conjugated (oligo)thiophenes. ${ }^{4,24}$ Organic polymeric structures are strongly dependent on marginal factors such as synthetic procedures, film morphology, poor and selective solvent solubilization, etc. Those have clear influence in the polymer behaviour in the way they change their structural properties thus affecting the emission properties. In parallel with these studies on polymers, oligomeric conjugated systems have been used as a way to obtain more information on the spectroscopic and photophysical properties together with mechanisms of energy transfer.

Thiophene oligomers and polymers are amongst the most well studied group of compounds in conjugated organic materials. ${ }^{1,3,4,24}$ However in general, oligo- and polythiophenes display more effective decay pathways than photon emission, such as thermal decay and intersystem-crossing. ${ }^{25,26}$ Synthetic strategies to overcome the low fluorescence quantum yields and improve the emission efficiency of oligo- and 
polythiophenes include copolymerization with highly fluorescent moieties. ${ }^{27}$ It is in this context that we have designed the new 2,4,5-trithienyl-imidazole derivatives.

Triaryl(heteroaryl)- imidazole $\mathrm{i}^{5-23}$ based chromophores have received increasing attention due to their distinctive linear and nonlinear optical properties and also due to their excellent thermal stability in guest-host systems. Besides their classical applications in medicinal chemistry, ${ }^{28} 2,4,5$-triaryl(heteroaryl)-imidazoles play also important roles in materials science due to their optoelectronic properties. ${ }^{5-23}$ Therefore they have found application as nonlinear optical materials, ${ }^{5-10,13,18}$ fluorescent chemosensors, ${ }^{14,20}$ two-photon absorbing molecules ${ }^{11}$ and thermally stable luminescent materials for several applications such as OLEDs. ${ }^{15,22}$

New material properties can be achieved when new conjugated systems are composed by different heterocyclic nuclei which allow the fine tuning of important physical and/or photophysical properties. As a result of the optical and conductive properties, conjugated materials containing thiophene and imidazole heterocycles have found many applications including those described above..$^{5-23}$

Despite all these promising properties for optical applications, only a very few publications concerning the synthesis and characterization of triaryl(heteroaryl)imidazoles can be found available in the literature. Owing to synthetic difficulties, most of the imidazoles developed so far, namely 2,4,5-triaryl(heteroaryl)-imidazoles, only possess short conjugation pathways (spacers) such as phenyl, thienyl or thiazolyl. ${ }^{5-10,13,18}$ Usually the 2,4,5-trisubstituted imidazole derivatives reported in the literature are 2,4,5triarylimidazoles or 4,5-diarylimidazoles substituted by a thiophene or a thiazole ring at position 2. 
Recently, we reported the synthesis and characterization of (oligo)thienyl- and arylthienyl- imidazo-phenanthroline derivatives and it was seen that they exhibited interesting optical properties such as good solvatochromic and nonlinear optical (NLO) properties, and high thermal stability. ${ }^{29,30}$ In the present work the synthesis and the photophysical characterization of new 2,4,5-tri(oligo)thienylimidazoles was undertaken to gain detailed understanding of the relationship between the structure and its fluorescence properties. It is expected that the use of electron-rich five-membered heteroaromatics such as thiophenes and imidazoles in the conjugation pathway should minimize the distortion of conjugation between the imidazole ring and the aromatic ring at the position 2, thus enhancing conjugation and the charge transport properties along the oligomer backbone. ${ }^{15}$

To the best of our knowledge, this is the first report on the synthesis and evaluation of the photophysical properties of 2,4,5-tri(oligo)thienyl-imidazole derivatives. We are aware of only two works reporting the synthesis of 2,4,5-tri-(2-thienyl)-imidazole and no photophysical characterization for this compound was given. ${ }^{31,32}$ 


\section{Experimental Section}

The synthesis and physical characterization of the investigated compounds (Scheme 1) are given as supporting information.

All the solvents used were of spectroscopic or equivalent grade. For the absorption and emission experiments in ethanol, the concentrations of the solutions ranged from $1 \times 10^{-5}$ to $10^{-6} \mathrm{M}$. Absorption and fluorescence spectra were recorded on Shimadzu UV-2100 and Horiba-Jobin-Ivon SPEX Fluorog 3-22 spectrometers respectively. The fluorescence spectra were corrected for the wavelength response of the system. The molar extinction coefficients $\left(\varepsilon_{S S}\right)$ were obtained at absorption maxima from the slope of the plot of the absorption vs. the concentration using six solutions of different concentrations (correlation values $\geq 0.999$ ). The fluorescence quantum yields were measured using bithiophene ( $\phi_{\mathrm{F}}=0.014$ in ethanol), terthiophene $\left(\phi_{\mathrm{F}}=0.054\right.$ in ethanol), quaterthiophene $\left(\phi_{\mathrm{F}}=0.18\right.$ in ethanol), quinquethiophene $\left(\phi_{\mathrm{F}}=0.33\right.$ in $\left.\mathrm{MCH}\right)$ as standard. ${ }^{33}$ Fluorescence decays with nanosecond ${ }^{34}$ and picosecond ${ }^{35}$ time-resolution were measured using home-built time correlated single photon counting (TCSPC) systems described elsewhere. Alternate measurements of the pulse profile at the excitation wavelength and the sample emission were performed until $5 \times 10^{3}$ counts at the maximum were reached. The fluorescence decays were analysed using the modulating functions method of Striker with automatic correction for the photomultiplier "wavelength shift". ${ }^{36}$ The experimental setup used to obtain triplet spectra and triplet yields has been described elsewhere. ${ }^{34,37}$ First-order kinetics were observed in all cases for the decay of the lowest triplet state. The triplet molar absorption coefficients $\left(\varepsilon_{\mathrm{TT}}\right)$ were obtained by the energy transfer methods ${ }^{38}$ and were determined using naphthalene, $\varepsilon_{\mathrm{T}}=24500 \mathrm{M}^{-1} \mathrm{~cm}^{-1}(415 \mathrm{~nm}),{ }^{39}$ as triplet energy donor. 
The concentrations for the compounds studied were $2 \times 10^{-5} \mathrm{M}$ and they were dissolved in $10^{-4} \mathrm{M}$ ethanol solution of naphthalene. Details on the experimental procedures and equations used can be found in ref. ${ }^{37}$ The intersystem crossing yields for the compounds $\left(\phi_{\mathrm{T}}\right)$ were obtained by comparing the $\Delta \mathrm{OD}$ at $525 \mathrm{~nm}$ of benzene solutions optically matched (at the laser excitation wavelength) of benzophenone (standard) and of the compound has described elsewhere. ${ }^{37}$ Room-temperature singlet oxygen phosphorescence was detected at $1270 \mathrm{~nm}$ with a Hamamatsu R5509-42 photomultiplier cooled to $193 \mathrm{~K}$ in a liquid nitrogen chamber (Products for Research model PC176TSCE-005) after laser excitation at $355 \mathrm{~nm}$ in an adapted Applied Photophysics flash kinetic spectrometer. Equipment and procedures were elsewhere reported. ${ }^{34,37}$

DFT calculations were carried out by means of the Gaussian03 program $^{40}$ and using the

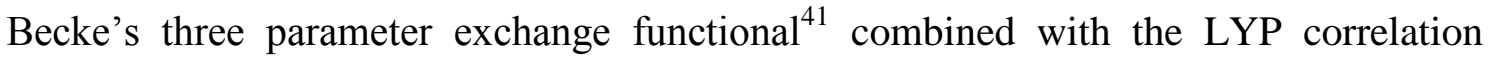
functional (B3LYP) ${ }^{42}$. The $3-21 \mathrm{G}^{*}$ Gaussian atomic basis set was used to optimize the geometry of the ground, $S_{0}$, and lowest lying singlet, $S_{1}$, and triplet, $T_{1}$, states and to compute the electronic structure at the minima found. Optimal geometries were determined on isolated entities in a vacuum and no conformation restrictions were imposed. For the resulting optimized geometries, time dependent DFT (TDDFT) was applied to predict the vertical electronic excitation energies. ${ }^{43-45}$ TDDFT calculations were carried out using the same functional and basis set as those in the previously optimized molecular geometries. For the singlet excited state geometry optimization $\left(S_{1}\right)$ the DFT approach was not applied due to the very high computational effort involved in calculating the necessary gradients. In this particular case we have used a Hartree-Fock based single-excitation restricted configuration interaction (RCIS) ${ }^{46}$ method with the $3-21 \mathrm{G}^{*}$ basis set to optimize the geometry of the first singlet excited 
state. Then we used TDDFT to calculate the transition energy between the electronic $\mathrm{S}_{1}$ and $\mathrm{S}_{0}$ states from the relaxed $\mathrm{S}_{1}$ geometry. Molecular orbitals contours were plotted using Molekel 5.3. ${ }^{47}$ 


\section{Results}

Synthesis. In order to compare the effect of one or two di(2-thienyl) imidazole moieties on the photophysical properties of imidazoles 3-5, as well as the effect of the length and the nature of the $\pi$-conjugated bridge, formyl-(oligo)thiophenes 1-2 containing one or two formyl groups were used as precursors of (oligo)thienyl-imidazoles 3-5.

Therefore, compounds 3-5 with either thienyl, bithienyl, terthienyl or arylthienyl (substituted with $\mathrm{H}$ or alkoxy) linked to the 4,5-di(2-thienyl)-imidazole system, were synthesized in good to excellent yields (67-90\%, Table S1 supporting information), through the condensation reaction ${ }^{48}$ of di-2-thienylethanodione with formyl(oligo)thiophene derivatives 1-2 and ammonium acetate in refluxing glacial acetic acid for $15 \mathrm{~h}$, (Scheme 1). Compounds 1a-b were commercially available and the synthesis of precursors 1c-e and 2, have been reported by us, recently, through several methods. ${ }^{29,49-51}$

Compound 3a was prepared by us in a $84 \%$ yield using only one step, from commercially available reagents, using simple work-up procedures, resulting in good yielding preparation and ease of isolation of these derivative. The synthesis of compound 3a had been reported previously through different synthetic strategies: by heating the corresponding triaryl-2,4-diazapentadienes with a stoichiometric amount of $t$-BuOK in DMSO in the presence of oxygen followed by reaction with a solution of ammonia in $95 \%$ EtOH and ammonium chloride ${ }^{31}$ or with liquid ammonia. ${ }^{32}$ In the two approaches, the imidazole derivative was obtained in a lower yield after several reaction steps.

$\langle$ Scheme 1> 
Earlier studies concerning the synthesis and characterization of the optical properties of triaryl(heteroaryl)-imidazoles showed that the fluorescence properties of these derivatives could be tuned by substitution of the aryl group at the position 2 by a 5 membered heterocyclic ring such as thiophene or thiazole. The comparative study of the fluorescence properties for several 2,4,5-triaryl(heteroaryl)-imidazoles showed that the substitution of the 2-phenyl ring in 2,4,5-triphenyl-imidazole by a thiophene or a thiazole improved the quantum yields, from 0.48 to 0.86 in the case of thiophene or from 0.48 to 0.57 in the case of the thiazole, due to a more planar conformation of the heterocyclic imidazoles. $^{12}$

Thermal stability of imidazoles 3-5. All the 2,4,5-trisubstituted thienyl-imidazoles 3-5 are thermally stable, high melting materials. Thermal stability of compounds $\mathbf{3 - 5}$ was estimated by thermogravimetric analysis (TGA), measured at a heating rate of $20{ }^{\circ} \mathrm{C}$ $\min ^{-1}$ under a nitrogen atmosphere. The results obtained revealed the exceptional thermal stability for all compounds, which could be heated up to $\mathrm{T}_{d}=331-452{ }^{\circ} \mathrm{C}$ (imidazole derivatives 3a-d) or $440-479{ }^{\circ} \mathrm{C}$ (bis-imidazole derivatives 4-5). The increase of the number of thiophenic units, e.g., as in $\mathbf{3 b}\left(\mathrm{T}_{d}=390{ }^{\circ} \mathrm{C}\right)$ and $\mathbf{3 d}\left(\mathrm{T}_{d}=352\right.$ ${ }^{\circ} \mathrm{C}$ ) and especially the incorporation of a second dithienylimidazo moiety, e.g. comparison of $\mathbf{3 b}\left(\mathrm{T}_{d}=390{ }^{\circ} \mathrm{C}\right)$ with $\mathbf{4}\left(\mathrm{T}_{d}=440{ }^{\circ} \mathrm{C}\right)$, leads to highly thermal stable materials.

Photophysical characterization. The investigated 2,4,5-oligothienyl substituted imidazoles can be divided in two groups (Scheme 1). In the first, in the position 2 of the 
imidazole ring the number of thienyl units (n) is increased from 1 to 3 (3a-d); in the second, the central bithiophene unit is end-capped by two thienyl-imidazole moieties (4); additionally a structure consisting on the replacement of a central thienyl unit (in oligomer 4) by a phenyl moiety (5) was also investigated.

Singlet-State. The absorption spectra of the oligothienyl-imidazoles in ethanol solution at room and low temperature (here represented by the fluorescence excitation spectra) are shown in Figure 1. At room temperature the spectra are broad and structureless. In solution, the absorption (band and wavelength maxima) red-shifts with the incremental increase of the thiophene units. Upon decreasing the temperature, an increase in the vibrational structure and a red-shift of the spectra occurs, with changes in absorption maxima ranging from $\approx 13 \mathrm{~nm}(\mathbf{3 a})$ to $\approx 24 \mathrm{~nm}(\mathbf{4})$, see Table 1 . However, the most dramatic changes in the room vs. the low temperature spectra are observed for the longer thienyl-containing compounds of the two series, $\mathbf{3 d}$ and $\mathbf{4}$, with a clear increment of the vibronic resolution at $77 \mathrm{~K}$. In view of the similar behaviour found for the oligothiophene counterparts, ${ }^{33}$ this suggests that the oligothiophene unit dominates the excited state characteristics of these compounds.

\section{$<$ Figure 1 >}

$<$ Table 1>

In Figure 2 the fluorescence emission spectra in solution at $293 \mathrm{~K}$ and $77 \mathrm{~K}$ are shown. Upon going from $293 \mathrm{~K}$ to $77 \mathrm{~K}$ there is a marked increase in the vibrational structure of the spectra, with exception of the simplest member of the series, 3a. Contrary to what was seen in the absorption, in the emission a blue-shift ranging from $\approx 3 \mathrm{~nm}(4)$ to $\approx 33$ 
nm (3c) was observed upon going from $293 \mathrm{~K}$ to $77 \mathrm{~K}$. A similar behaviour was previously found for naphthalene end-terminated oligothiophenes which was attributed to the ground-state to which the more planar excited-state (quinoidal-like) deactivates. ${ }^{52}$

$<$ Figure 2>

Fluorescence decay times were measured in solution at room temperature and were all seen to be single-exponential in a nanosecond time scale (Table 2). Fluorescence decays obtained in a ps-time domain ( 3 ps time resolution) were also collected at the maximum emission wavelength and no additional fast components were found, thus confirming the data obtained with ns-time resolution (Figure 3). This agrees with the adoption of a rigid and possibly quinoidal-like structure [involving a partial and extended conjugation between the oligothienyl unit(s) and the thienyl-imidazole(s) end unit(s)] in the excitedstate.

$<$ Figure 3>

$\langle$ Table 2>

Triplet-state and singlet oxygen sensitization- Upon laser flash photolysis at $355 \mathrm{~nm}$ of degassed solutions of the oligothienyl-imidazoles in ethanol at $293 \mathrm{~K}$, a depletion of the ground-state absorption was observed at lower wavelengths together with an intense transient absorption band with maxima at longer wavelengths (Figure 4). The triplettriplet absorption spectra are broad suggesting delocalization of the triplet excited state 
due to conjugation along the oligomer chain. From Table 1 and Figure 4 it can be observed the constancy in the $\mathrm{T}_{1} \rightarrow \mathrm{T}_{\mathrm{n}}$ wavelength maxima when going from $\mathbf{3 b}$ to $\mathbf{3 d}$. In contrast with their analogue counterparts, the $\alpha$-oligothiophenes and the end-substituted cyano-oligothiophenes, ${ }^{33,34}$ (where an increase in the $T_{1} \rightarrow T_{n}$ maxima was observed with the number of thiophene units in the oligomer chain) with the first family of the investigated compounds no such trend was observed. This is particularly valid for $\mathbf{3 b}$ and 3d displaying a similar transient triplet-triplet absorption maximum; see Figure 4 and Table 1. This suggests an identical degree of delocalization of the triplet state of these compounds.

\section{$<$ Figure 4>}

The phosphorescence of these compounds in ethanol glasses at $77 \mathrm{~K}$ was also investigated and the only case where we were able to detect phosphorescence was with 3a (Figure 5). In this case, a structured emission band with maximum at 523 and 565 $\mathrm{nm}$ and a shoulder at $635 \mathrm{~nm}$ was observed. The phosphorescence excitation spectra of 3a matched the room temperature absorption spectra with exception of the increased vibrational structure and a shift of $\approx 7 \mathrm{~nm}$. The observation of phosphorescence for the shortest member of this series of compounds agrees to what was seen for short thiophene oligomers ${ }^{33,34,53,54}$ and also a polythiophene ${ }^{55}$ were phosphorescence was observed. 
Singlet oxygen formation quantum yields $\left(\phi_{\Delta}\right)$ were obtained by photolysis of aerated ethanol solutions of the oligothienyl-imidazoles. The $\phi_{\Delta}$ values were determined by plotting the initial singlet oxygen phosphorescence intensity as a function of the laser dose and comparing the slope with that obtained with $1 H$-phenalen-1-one in ethanol $\left(\phi_{\Delta}=0.97\right)^{56}$ as the standard.

$<$ Figure 5>

Theoretical Ground and Excited State Optimized Geometries - To gain more detailed information on the electronic properties of the compounds under investigation the geometry of oligomers 3a, 4 and $\mathbf{5}$ was optimized at the DFT//B3LYP/3-21G* level. ${ }^{41,42}$ Figure 6 presents the ground-state optimized geometry together with the frontier molecular orbital contours around the band-gap for oligomers $\mathbf{3 a}, \mathbf{4}$ and $\mathbf{5}$.

$<$ Figure 6>

It is seen that for oligomers $\mathbf{3 a}$ and $\mathbf{4}$, a planar conformation is adopted by the thienylimidazole units with the exception of the thienyl units linked in position 4- of the imidazoles rings that displays a dihedral angle of $\approx 55^{\circ}$ with respect to the planar backbone (see Figure 6). For oligomer 5 a dihedral angle of $\approx 24^{\circ}$, between the planes formed by the (2'-thienyl)imidazole and the 4' '-aryl[5(thienyl)imidazole] moieties, was found thus showing that the oligomer backbone is slightly twisted. Again, in this case, the thienyl units linked in position 4- of the imidazoles ring adopt a dihedral angle of $\approx 55^{\circ}$ with respect to the planar moieties. Although the oligomer backbone is twisted, this does not seem to affect electron delocalization as showed by the red-shift in the 
predicted (as discussed in the following section) and experimental absorption maxima when compared to oligomer 3a. This is also corroborated by the analysis of the topologies of the molecular orbitals showing that the electron density of the highest occupied molecular orbital (HOMO) is distributed through the backbone of the oligomers under investigation (see Figure 6). From the lowest unoccupied molecular orbitals (LUMO) it is clear that the electron density in the $\mathrm{C}-\mathrm{C}$ bonds connecting the central thienyl and imidazole units increases. This increase is extensive for the nonplanar thienyl unit thus showing that an extended delocalization for this thienyl unit occurs, which is compatible with the previously mentioned quinoidal-like structure adopted in the excited state $\left(\mathrm{S}_{1}\right)$.

In order to get further details on the excited state properties of $\mathbf{3 a}$, the geometries of the singlet $\left(\mathrm{S}_{1}\right)$ and triplet $\left(\mathrm{T}_{1}\right)$ states were optimized (see Figure 7$)$. The calculated excited state geometries show that both for $S_{1}$ and $T_{1}$ the thienyl units in positions 4,5 of the imidazole ring are slightly out of the plane formed by the 2-(2'-thienyl)imidazole core (by $\approx 25^{\circ}$ for $S_{1}$ and $\approx 13^{\circ}$ for $T_{1}$ ). These results show that, in comparison with the ground state geometry, in the excited state an overall increase in planarization is achieved which is again in agreement with the adoption of a quinoidal structure in the excited state. Also worth noting is the fact that in the geometry of the triplet state, the reduction of the dihedral angle is more pronounced, which again is in agreement with the previously observed delocalization of the triplet excited state.

$<$ Figure 7> 


\section{Discussion}

The present compounds were introduced in order to gain improved results relative to the oligothiophene counterparts ( $\alpha$ n's) regarding its potential use in molecular electronics. In this way the subsequent discussion will be partially focussed on the comparison with the analogs bithiophene $(\alpha 2)$ and terthiophene $(\alpha 3)$.

The spectral data on group 1 compounds shows that the incremental addition of thienyl units increases the maxima wavelength of absorption and fluorescence at both room and low temperatures, Table 1 . The same is not valid for the transient triplet-triplet maxima, for which the wavelength maximum only increases from $\mathbf{3 a}$ to $\mathbf{3 b}$, then remaining constant with a value of $610 \mathrm{~nm}$, Table 1. Comparison of the transient maxima of these compounds (and also of 4 and 5) with $\alpha 2$ and $\alpha 3$ clearly demonstrates that the latter have more localized triplet states which shows that with the thienyl-imidazole compounds there is more delocalization in the triplet state induced by the contribution of the imidazole unit(s).

To provide a deeper insight into the nature of the UV-vis absorptions, observed experimentally for the oligomers, the lowest energy electronic excited states (in terms of dominant one-electron vertical excitation) were calculated at the B3LYP/3.21G* level using the TDDFT approach on their previously optimized ground-state molecular geometries. The predicted transitions for oligomers 3a $(354 \mathrm{~nm}), 4(458 \mathrm{~nm})$ and $\mathbf{5}(422$ $\mathrm{nm}$ ) are slightly red-shifted when compared to the experimental values (see Table 1). However, overestimation by $\approx 0.2 \mathrm{eV}$ of the lowest excitation energy by TDDFT calculations was reported for sulfur containing compounds and conjugated systems. ${ }^{57-61}$ In this case deviations much below $0.2 \mathrm{eV}$ (from $0.02 \mathrm{eV}, \mathbf{3 a}$, to $0.04 \mathrm{eV}, 4$ ) were 
observed, thus demonstrating a good agreement between the experimental and theoretical data and providing convincing support for the calculated ground-state molecular geometries. It is also noteworthy that the calculated wavelengths and the reduction in the band-gap on going from oligomer $\mathbf{3}$ to $\mathbf{4}$ and 5, seen in Figure 6, reproduces, with good accuracy, the spectral red-shift observed with the increase of the oligomer chain (Table 1 and Figure 1).

Also relevant to this discussion is the observation that the absorption wavelength maxima at $293 \mathrm{~K}$ for 3a is identical to that of $\alpha 3$ (see Table 1) which shows that the thienyl-imidazole unit adds the equivalent of two thiophene units to the $\pi$-conjugation path of the $S_{1}$ state of these compounds. In the case of $\mathbf{4}$ and $\mathbf{5}$ there is a clear increase of the absorption, emission and transient triplet-triplet maxima relative to the $\alpha 2$ and $\alpha 3$ counterparts; the values, depending on the state considered (singlet excited or transient triplet), more closely can be considered to involve four or five thiophene units. ${ }^{33}$

The singlet and triplet excited state radiative transitions (fluorescence and phosphorescence) of oligomer 3a were also investigated by means of the TDDFT approach on the previously optimized excited state $\left(S_{1}\right)$ and ground-state geometries. The predicted values $420 \mathrm{~nm}\left(\mathrm{~S}_{0} \leftarrow \mathrm{S}_{1}\right)$ and $504 \mathrm{~nm}\left(\mathrm{~S}_{0} \leftarrow \mathrm{T}_{1}\right)$ are in good agreement with the experimental values (426 $\mathrm{nm}$ and $523 \mathrm{~nm}$ respectively, Table 1) and once more provide support for the calculated geometries (see Figure 7).

The photophysical parameters obtained in solution at $293 \mathrm{~K}$ and $77 \mathrm{~K}$ are presented in Table 2. Inspection of Table 2 shows that, as a general trend, the radiationless quantum yields $\left(\phi_{\mathrm{IC}}+\phi_{\mathrm{T}}\right)$ are the main deactivation pathways of the excited-state of these compounds. The intersystem crossing quantum yields $\left(\phi_{\mathrm{T}}\right)$ values are higher than the 
fluorescence quantum yields, which is in agreement with the situation observed with the analogues $\alpha{ }^{\prime} s^{33}$ where the intersystem crossing process is more efficient than the deactivation radiative channels.

From Table 2 it is possible to observe that the fluorescence quantum yields increases from 3a to $\mathbf{3 b}$ then remaining constant $(\mathbf{3 d})$. The increase in $\phi_{\mathrm{F}}$ with the number of thienyl units in the oligomer backbone agrees with the general trend observed with the oligothiophenes and its derivatives. ${ }^{33}$ However, there is a clear difference in which regards the dominant deactivation process in these compounds when compared with the an's. Indeed it is clear from Table 2, where the photophysical data in ethanol are presented for the bithiophene ( $\alpha 2)$ and terthiophene ( $\alpha 3$ ), that the analogues $\mathbf{3 b}$ and $\mathbf{3 d}$ present much higher $\phi_{\mathrm{F}}$ values and lower $\phi_{\mathrm{T}}$ values. Moreover in the case of $\mathbf{3 b}$ and of its ethoxylated derivative (3c) the internal conversion yield represents $\sim 20 \%$ of the contribution to the decay process, whereas with $\alpha 2$ this value was found to be negligible, $\sim 0 .^{33}$ The introduction of the thienyl-imidazole unit at both ends $(\alpha, \alpha$, positions) of a bithiophene unit (4) decreases one half the $\phi_{\mathrm{F}}$ value relative to the mono substituted $\mathbf{3 b}$, see Table 2 .

Upon cooling (from $293 \mathrm{~K}$ to $77 \mathrm{~K}$ ), the fluorescence quantum yield increases for all the investigated compounds, with exception of 3c. This increase of the $\phi_{F}$ values is also paralleled with the thiophene oligomers, where an increase of this value is observed, see Table 2. ${ }^{33}$ This was attributed to the conformational degrees of freedom of these oligomers at $293 \mathrm{~K}$, which is reduced at $77 \mathrm{~K}$, thus enhancing the contribution from the radiative decay channel. For 3c a slight decrease in $\phi_{\mathrm{F}}$ was observed upon cooling suggesting that the introduction of the ethoxy group induces that similar conformations 
are seen in the excited state at $293 \mathrm{~K}$ and $77 \mathrm{~K}$. Moreover, comparison between the $\mathbf{3 b}$ and 3c oligomers shows that the structural change between them lies in the endsubstituted electron-donor group EtO. A similar behaviour, consequence of similar substitution, was found for bithienyl-benzothiazole derivatives which was also mirrored in its photophysical behaviour ( $\phi_{\mathrm{F}}$ at $293 \mathrm{~K}$ vs. $77 \mathrm{~K}$ ). ${ }^{62}$ In that situation, for the unsubstituted bithienyl-benzothiazole, the $\phi_{\mathrm{F}}$ value increases when going from $293 \mathrm{~K}$ to $77 \mathrm{~K}$ while for the end-terminated $\mathrm{MeO}$ and EtO-(bithienyl-benzothiazole) a modest decrease in $\phi_{\mathrm{F}}$ was seen when going to $77 \mathrm{~K} .{ }^{62}$ The increase in $\phi_{\mathrm{F}}$ at $77 \mathrm{~K}$, with the unsubstituted bithienyl-benzothiazole, was explained as a consequence of a reduction of the internal conversion channel due to a decrease in the coupling for the radiationless modes occurring between the $\mathrm{S}_{1}$ and $\mathrm{S}_{0}$ states, whereas the decrease in $\phi_{\mathrm{F}}$ [endterminated $\mathrm{MeO}$ and EtO-(bithienyl-benzothiazole)] could then be attributed to the structural rigidity induced by the benzothiazole moiety minimizing the conformational changes from $293 \mathrm{~K}$ to $77 \mathrm{~K} .^{62}$

It is also worth noting that the fluorescence lifetimes are higher than those found for the corresponding oligothiophenes, $\alpha 2$ and $\alpha 3$, and more closely resemble the values displayed by the longer oligothiophenes, $\alpha 4-\alpha 7 .^{33}$ With all of the above it can be concluded that the imidazole-thienyl unit acts as an efficient substitute of two or more thienyl units with the additional increment on the values for the emission parameters: $\phi_{\mathrm{F}}$ and $\tau_{\mathrm{F}}$.

One of the important additional observation regarding the photophysical parameters of these compounds is that their triplet state occupation yield decreases when compared to the analogues $\alpha 2$ and $\alpha 3 .^{33}$ As happens with the fluorescence lifetimes, the $\phi_{\mathrm{T}}$ values 
more closely resemble those found for the longer oligothiophenes $\alpha 5$ and $\alpha 6$ indicating, once more, that a parallel could be made on the introduction of one (group 1) or two (group 2) thienyl-imidazole units as efficient substituents of two or three thiophene units.

An emissive triplet state was only found for the shortest member of the family with a low phosphorescence quantum yield $\left(\phi_{\mathrm{Ph}}=0.009\right)$ and a phosphorescence lifetime of 8 $\mu$ s (see Figure 5B). Although emission from the triplet state of small oligothiophenes (with $n=1-3$ ) has been reported, ${ }^{53}$ no quantum yields of phosphorescence have been presented for these and the sole exception seems to be the cyano $\alpha, \alpha^{\prime}$ terminated thiophene presenting a moderately high phosphorescence yield $\left(\phi_{\mathrm{Ph}}=0.14\right),{ }^{34}$ which is two orders of magnitude higher than that found for 3a indicating that, albeit the triplet state of this oligomer is being populated $(\sim 51 \%)$, it deactivates mainly through radiationless processes.

Singlet oxygen formation quantum yields, $\phi_{\Delta}$, were also obtained for the investigated oligothienyl-imidazoles (Table 2) and were found, within the experimental error, identical to the triplet intersystem-crossing yields. Indeed, for these oligomers the singlet oxygen formation efficiency $\left(S_{\Delta}=\phi_{\Delta} / \phi_{T}\right)$ is close to 1, indicating that they sensitize ${ }^{1} \mathrm{O}_{2}$ formation in good yields. These results clearly indicate efficient energy transfer from the oligomers triplet states to the ground-state oxygen.

Finally it is worth comment on the values for the rate constants. From Table 2 the values for the radiative $\left(\mathrm{k}_{\mathrm{F}}\right)$ and radiationless $\left(\mathrm{k}_{\mathrm{IC}}\right.$ and $\left.\mathrm{k}_{\mathrm{ISC}}\right)$ rate constants are all of the same order of magnitude which indicates that the processes are, amongst them, all competitive. The exception is, once more, compound $\mathbf{3 d}$ for which the intersystem 
crossing rate constant, $\mathrm{k}_{\mathrm{ISC}}$, dominates the deactivation pathway with a close resemblance with the behaviour and data found for $\alpha 3 .^{33}$

\section{Conclusions}

A variety of 2,4,5-trisubstituted thienyl-imidazoles 3 and bis-4,5-thienyl-imidazoles 4-5 have been synthesized, for the first time, in good to excellent yields from easily available formyl-(oligo)thiophenes 1-2 and low cost commercially available reagents, using simple and convenient procedures.

The electronic spectral and photophysical properties of this new family of 2,4,5trisubstituted thienyl-imidazole derivatives was investigated in solution and further combined and interpreted by means of density functional theory. From theory it was seen that the predicted transition energies values are in agreement with those obtained from optical data, thus supporting the optimized molecular geometries obtained for the oligomers. From the photophysical data in solution it was shown that these oligomers present significantly higher $\phi_{\mathrm{F}}$ values (one order of magnitude) than the corresponding oligothiophenes. It was also seen that, in marked contrast with the oligothiophenes, the imidazole substituted with oligothiophene moieties have, with the exception of $\mathbf{3 d}$, an efficient internal conversion deactivation channel. These facts, combined with the exceptional thermal stabilities, opens new perspectives related to the copolymerization of oligothiophenes with thienyl-imidazole units for potential use for applications such as light emitting devices.

Acknowledgments: Thanks are due to the Foundation for Science and Technology (FCT-Portugal) for financial support through the Centro de Química-Universidade do Minho (Project PTDC/QUI/66250/2006). FCT is acknowledged for a post-doctoral 
grant to J. Pina (SFRH/BPD/65507/2009) and a $\mathrm{PhD}$ grant to $\mathrm{R}$. Batista (SFRH/BD/36396/2007).

Supporting Information Available: Synthesis and characterization and Table S1 listing yields, IR and ${ }^{1} \mathrm{H}$ NMR spectra and $\mathrm{T}_{d}$ data for (oligo)thienyl-imidazoles 3-5. This material is available free of charge via the Internet at http://pubs.acs.org. 


\section{Tables}

Table 1. Spectroscopic properties for the oligothienyl-imidazoles and for the unsubstituted oligothiophenes in ethanol solution at room $(293 \mathrm{~K})$ and low $(77 \mathrm{~K})$ temperature. The underlined values are the wavelength maxima.

\begin{tabular}{|c|c|c|c|c|c|c|c|}
\hline Compound & $\begin{array}{c}\lambda_{\max }^{A b s}(\mathbf{n m}) \\
293 \mathrm{~K}\end{array}$ & $\begin{array}{c}\lambda_{\max }^{A b s}(\mathbf{n m}) \\
77 \mathrm{~K}\end{array}$ & $\begin{array}{c}\lambda_{\max }^{S_{0} \leftarrow S_{1}}(\mathbf{n m}) \\
293 \mathrm{~K}\end{array}$ & $\begin{array}{c}\lambda_{\max }^{S_{0} \leftarrow S_{1}}(\mathbf{n m}) \\
\mathbf{7 7 ~ K}\end{array}$ & $\begin{array}{l}\lambda_{\max }^{T_{1} \rightarrow T_{n}} \\
(\mathbf{n m})\end{array}$ & $\begin{array}{c}\varepsilon_{S S}{ }^{\mathrm{a}} \\
\left(\mathrm{M}^{-1} \mathrm{~cm}^{-1}\right)\end{array}$ & $\begin{array}{c}\varepsilon_{\mathrm{TT}}^{\mathrm{a}} \\
\left(\mathrm{M}^{-1} \mathrm{~cm}^{-1}\right)\end{array}$ \\
\hline $3 \mathbf{a}$ & 322 & 335 & 426 & 410 & 520 & 27910 & 11930 \\
\hline $3 \mathbf{b}$ & 367 & $370, \underline{385}, 405$ & 468 & $430, \underline{455}$ & 610 & 27330 & 7800 \\
\hline $3 c$ & 378 & $375, \underline{395}, 415$ & 468 & $\underline{435}, 465,495$ & 610 & 9970 & 14000 \\
\hline 3d & 400 & $397, \underline{420}, 445$ & 500 & $464, \underline{495}, 530$ & 610 & 10285 & 21600 \\
\hline$\alpha 2$ & 303 & $304, \underline{315}, 328$ & 358 & $340,347, \underline{358}, 375$ & 390 & 12540 & 13500 \\
\hline$\alpha 3$ & 352 & $354, \underline{372}, 388$ & $405, \underline{426}$ & $403, \underline{427}, 455$ & 460 & 23590 & 27000 \\
\hline 4 & 407 & $407, \underline{431}, 460$ & 513 & $476, \underline{510}, 547$ & 670 & 5360 & 12000 \\
\hline 5 & 385 & $387, \underline{405}, 430$ & 485 & $448, \underline{477}, 508$ & 650 & 7960 & 9500 \\
\hline
\end{tabular}

${ }^{\mathrm{a}}$ singlet $\left(\varepsilon_{\mathrm{SS}}\right)$ and triplet $\left(\varepsilon_{\mathrm{TT}}\right)$ molar extinction coefficients 
Table 2. Photophysical parameters including quantum yields (fluorescence, $\phi_{\mathrm{F}}$, internal conversion, $\phi_{\mathrm{IC}}$, triplet formation, $\phi_{\mathrm{T}}$, and sensitized singlet oxygen, $\left.\phi_{\Delta}\right)$, lifetimes $\left(\tau_{\mathrm{F}}, \tau_{\mathrm{T}}\right)$ and rate constants $\left(\mathrm{k}_{\mathrm{F}}, \mathrm{k}_{\mathrm{NR}}, \mathrm{k}_{\mathrm{IC}}, \mathrm{k}_{\mathrm{ISC}}\right)$ for the oligothienyl-imidazoles and for the unsubstituted oligothiophenes in ethanol at $293 \mathrm{~K}$ and $77 \mathrm{~K}$.

\begin{tabular}{|c|c|c|c|c|c|c|c|c|c|c|c|}
\hline Compound & $\begin{array}{c}\phi_{F} \\
(293 \mathrm{~K})\end{array}$ & $\begin{array}{c}\phi_{F} \\
(77 \mathrm{~K})\end{array}$ & $\begin{array}{c}\tau_{\mathrm{F}} \\
(\mathrm{ns})\end{array}$ & $\phi_{\mathrm{IC}}$ & $\overline{\phi_{\mathrm{T}}}$ & $\overline{\phi_{\Delta}}$ & $\begin{array}{c}\tau_{T} \\
(\mu \mathbf{s})\end{array}$ & $\begin{array}{c}\mathrm{k}_{\mathrm{F}}\left(\mathrm{ns}^{-1}\right) \\
293 \mathrm{~K}\end{array}$ & $\begin{array}{c}\mathrm{k}_{\mathrm{NR}}\left(\mathrm{ns}^{-1}\right) \\
293 \mathrm{~K}\end{array}$ & $\begin{array}{c}\mathrm{k}_{\mathrm{IC}}\left(\mathrm{ns}^{-1}\right) \\
293 \mathrm{~K}\end{array}$ & $\begin{array}{c}\mathrm{k}_{\mathrm{ISC}}\left(\mathrm{ns}^{-1}\right) \\
293 \mathrm{~K}\end{array}$ \\
\hline $3 a$ & 0.086 & 0.13 & 0.600 & 0.40 & 0.51 & 0.46 & 31.3 & 0.143 & 1.523 & 0.673 & 0.850 \\
\hline $3 \mathbf{b}$ & 0.28 & 0.43 & 0.920 & 0.18 & 0.54 & 0.50 & 60.2 & 0.304 & 0.783 & 0.196 & 0.587 \\
\hline $3 c$ & 0.26 & 0.22 & 0.740 & 0.2 & 0.54 & 0.53 & 96.2 & 0.351 & 1.00 & 0.270 & 0.730 \\
\hline 3d & 0.18 & 0.30 & 0.530 & 0 & 0.82 & 0.79 & 42.3 & 0.340 & 1.55 & 0 & 1.55 \\
\hline$\alpha 2$ & 0.014 & 0.04 & 0.046 & $\sim 0$ & $\sim 1$ & - & 100 & 0.300 & $\sim 21$ & 0.100 & $\sim 21$ \\
\hline$\alpha 3$ & 0.054 & 0.12 & 0.190 & $\sim 0$ & 0.96 & - & 91 & 0.280 & 4.98 & 0.030 & 5.1 \\
\hline 4 & 0.14 & 0.34 & 0.550 & 0.38 & 0.48 & 0.51 & 68.5 & 0.255 & 1.56 & 0.691 & 0.873 \\
\hline 5 & 0.25 & 0.40 & 0.910 & 0.43 & 0.32 & 0.27 & 86.2 & 0.275 & 0.824 & 0.473 & 0.352 \\
\hline
\end{tabular}




\section{Figures and scheme captions}

Figure 1- Absorption spectra for the oligothienyl-imidazoles in ethanol at $293 \mathrm{~K}$ (two top panels) and $77 \mathrm{~K}$ (two bottom panels).

Figure 2- Fluorescence emission spectra for the oligothienyl-imidazoles in ethanol at $293 \mathrm{~K}$ (two top panels) and $77 \mathrm{~K}$ (two bottom panels).

Figure 3- Fluorescence decays for oligomers $3 \mathbf{c}$ and $\mathbf{5}$ in ethanol obtained with $\lambda_{\text {exc }}=$ $423 \mathrm{~nm}$ and $\mathrm{T}=293 \mathrm{~K}$. For a better judgment of the quality of the fits, autocorrelation functions (A.C.), weighted residuals (W.R.) and chi-square values are also present as insets. The dashed line is the pulse instrumental response.

Figure 4- Transient triplet-triplet absorption spectra for the oligothienyl-imidazoles in ethanol at room temperature.

Figure 5- Phosphorescence emission spectra (A) and emission decay (B) for 3a in ethanol at $77 \mathrm{~K}$.

Figure 6- DFT//B3LYP/3-21G* optimized ground-state geometry together with the electronic density contours for the frontier molecular orbitals of oligomers $\mathbf{3 a}, \mathbf{4}$ and $\mathbf{5}$.

Figure 7- Schematic diagram with the DFT//B3LYP/3-21G* optimized lowest lying singlet $\left(\mathrm{S}_{0}\right)$ and triplet $\left(\mathrm{T}_{1}\right)$ geometries and the HF//RCIS/3-21G* singlet excited state geometry. Also shown for comparison the experimental and the TDDFT//B3LYP/3$21 \mathrm{G}^{*}$ predicted (in parenthesis) absorption, fluorescence and phosphorescence wavelength maxima.

Scheme 1. Synthesis of (oligo)thienyl-imidazoles 3-5. 
Figures

Figure 1

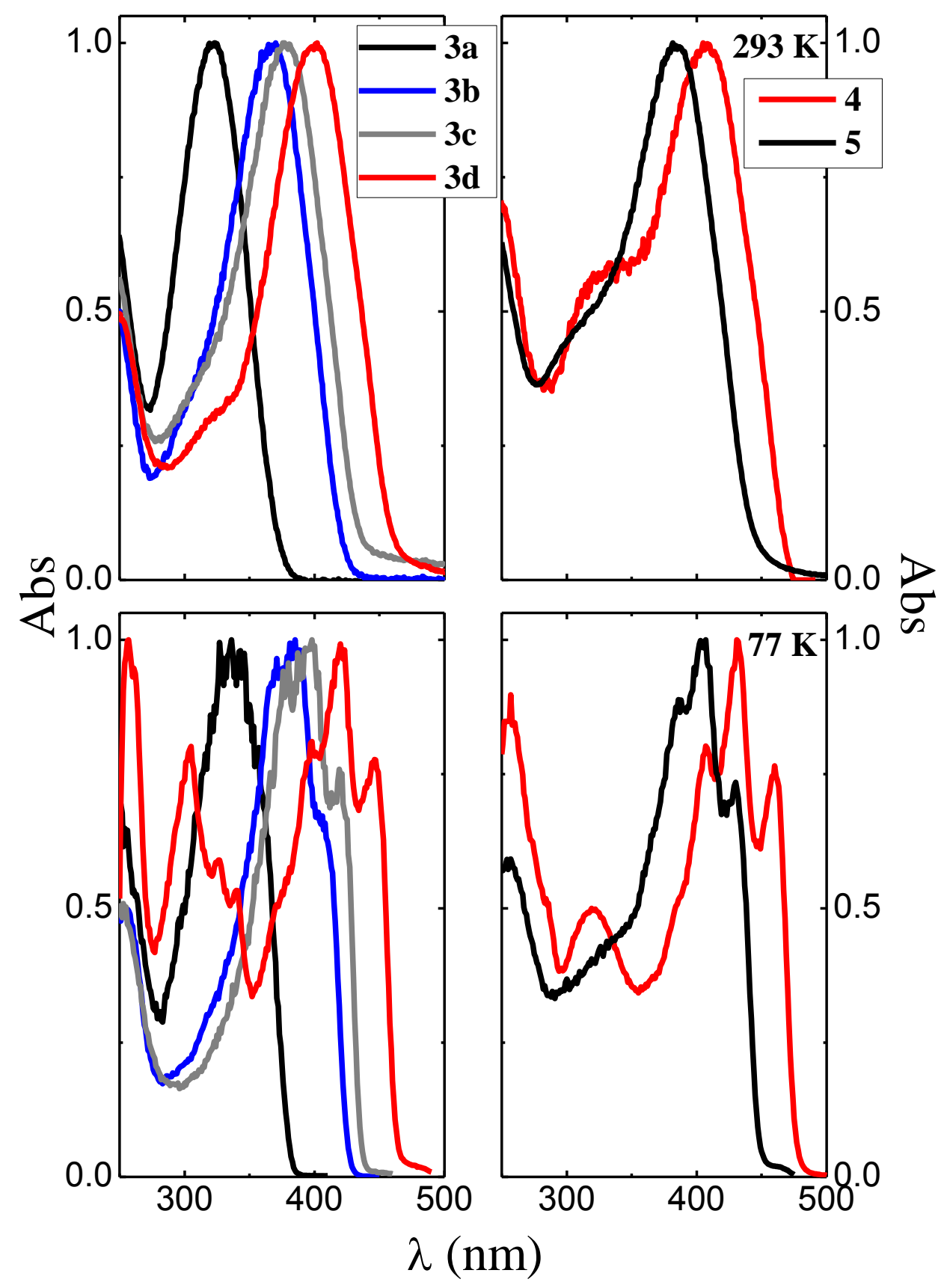


Figure 2

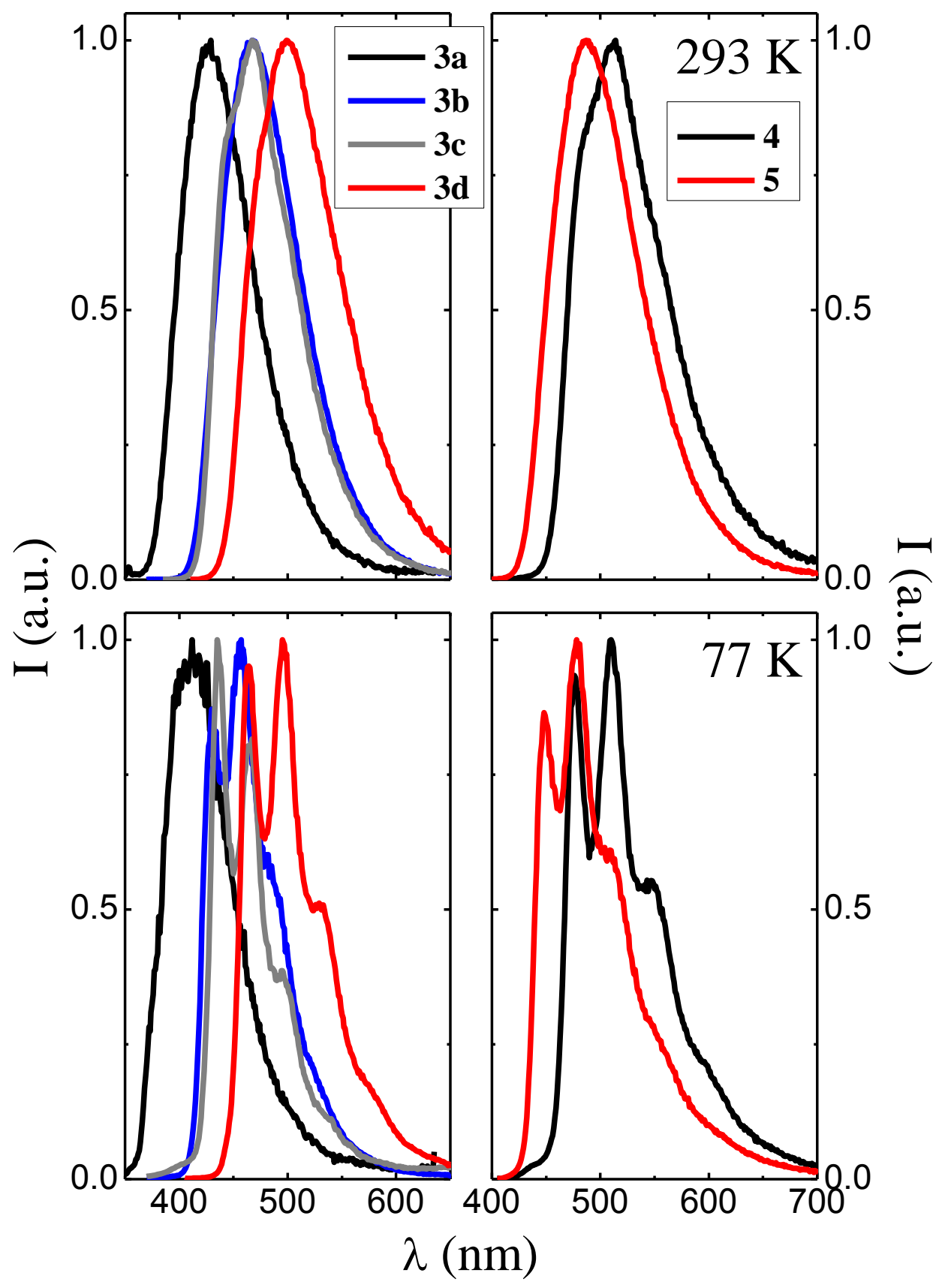


Figure 3
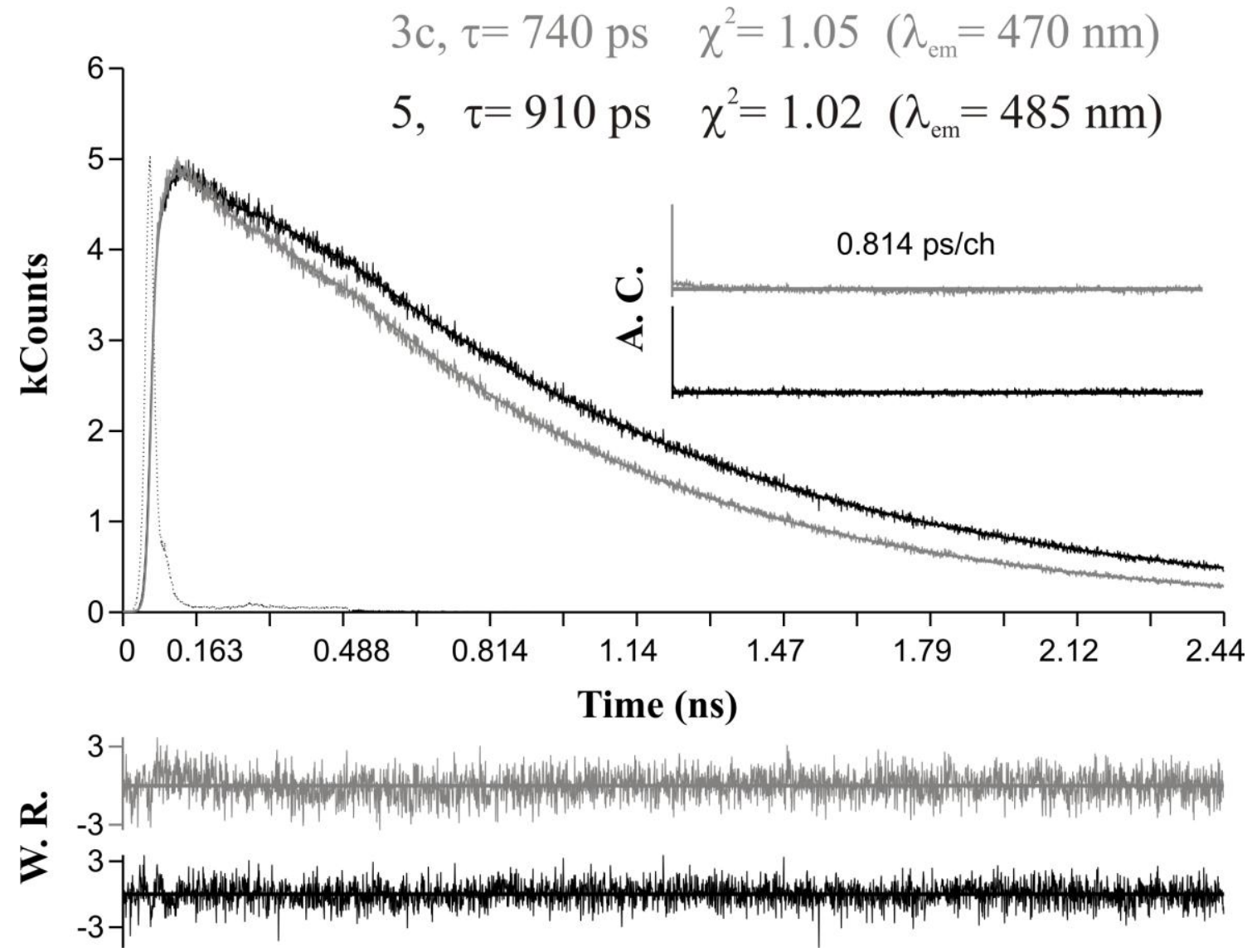
Figure 4

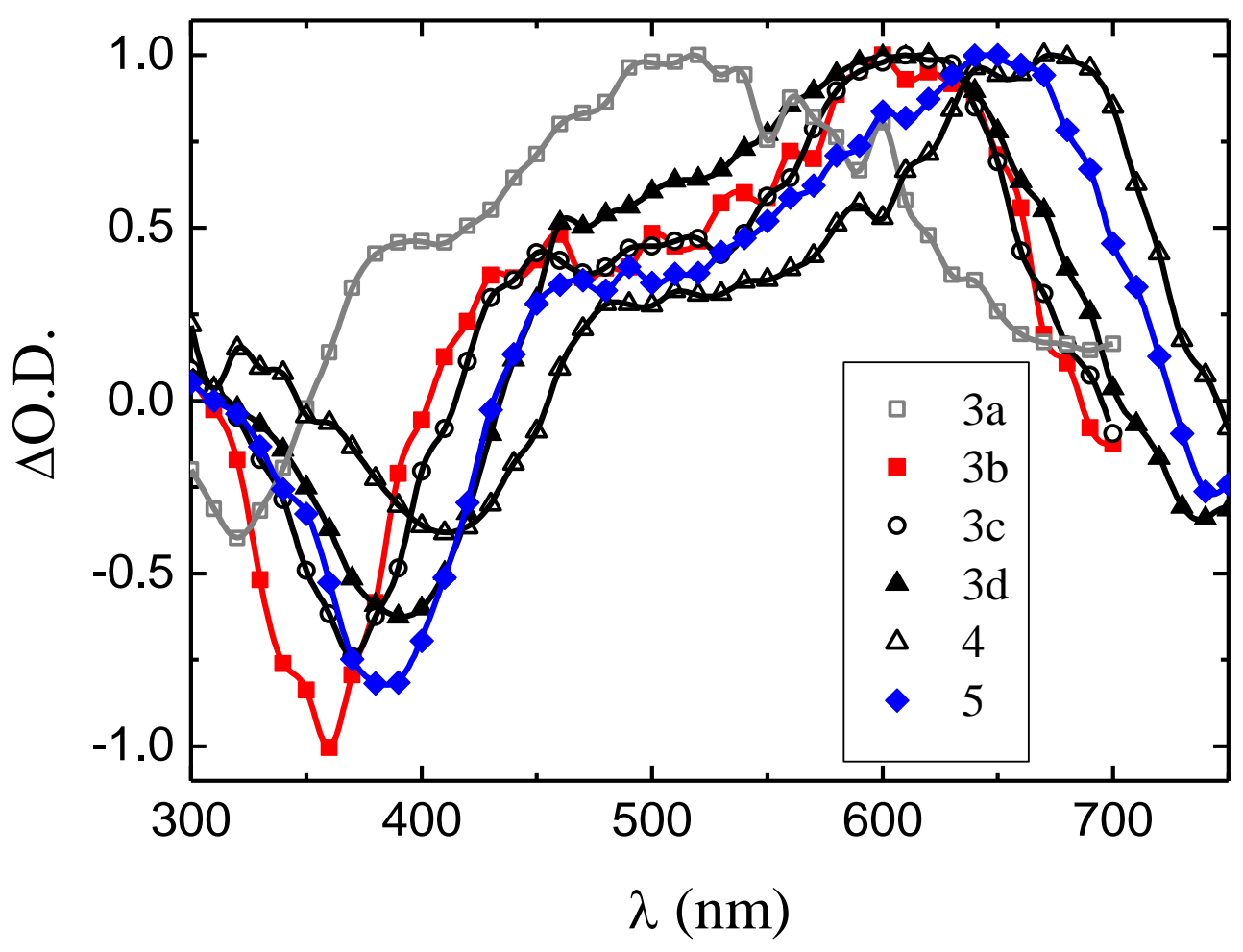


Figure 5
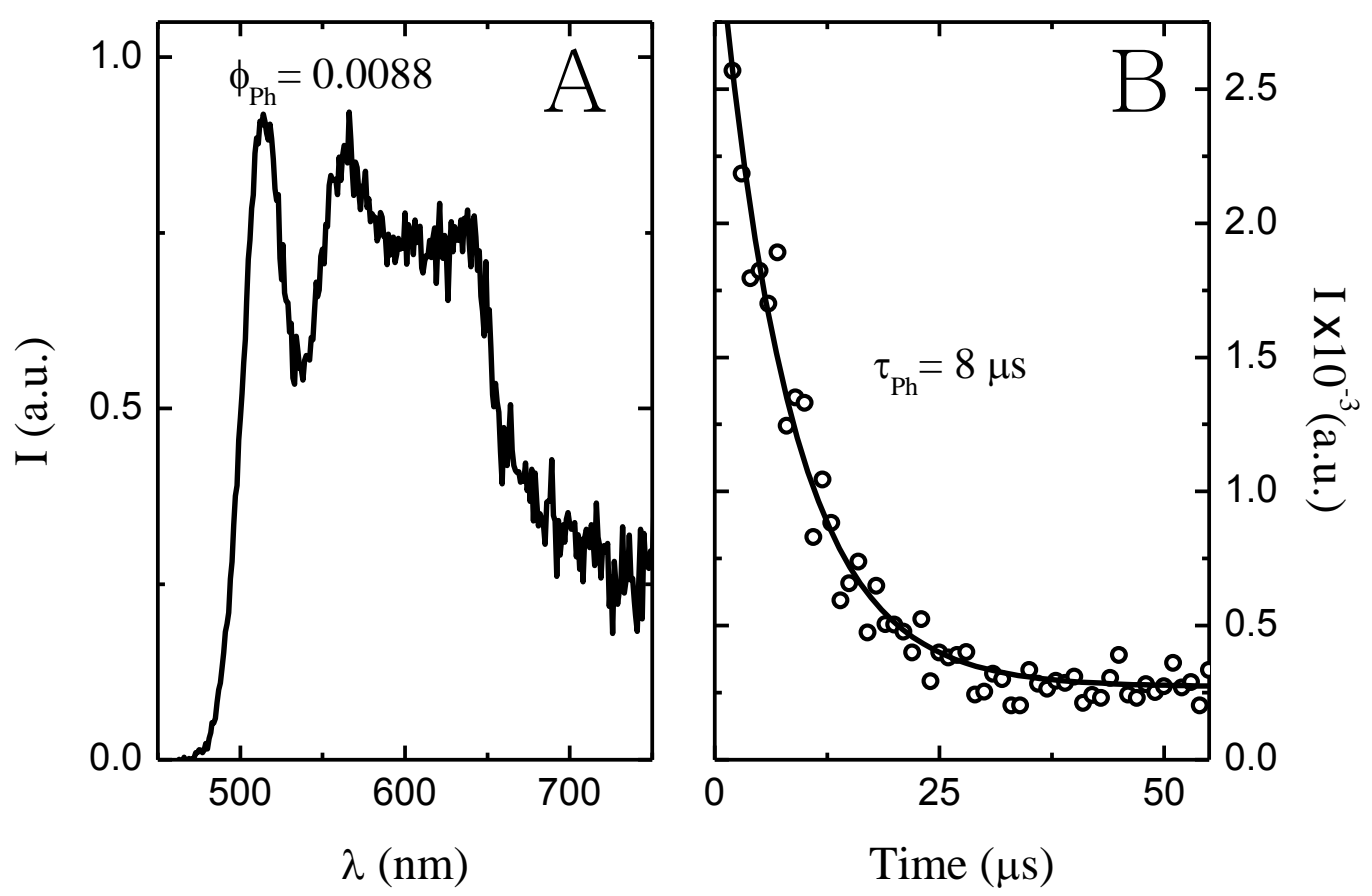
Figure 6

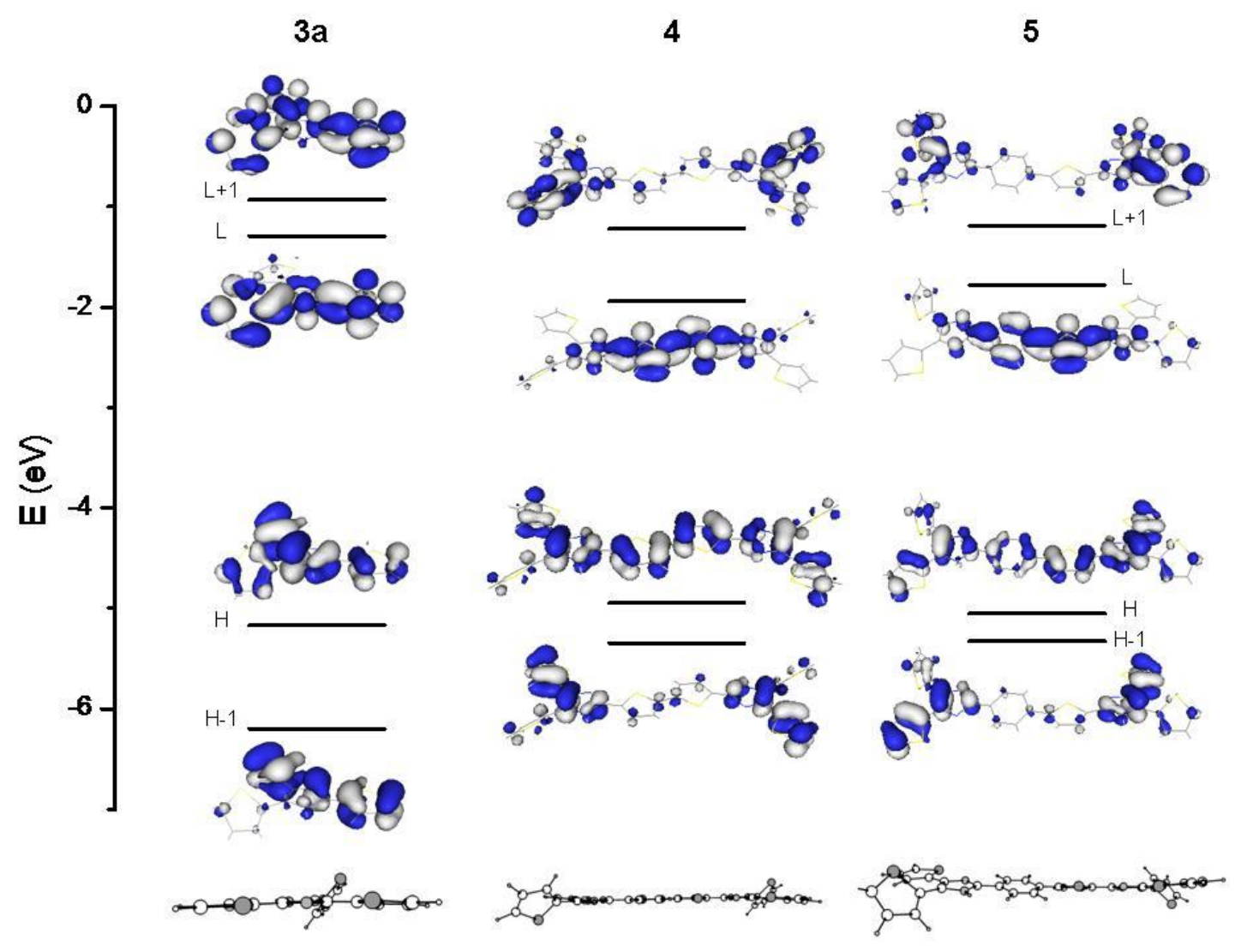


Figure 7

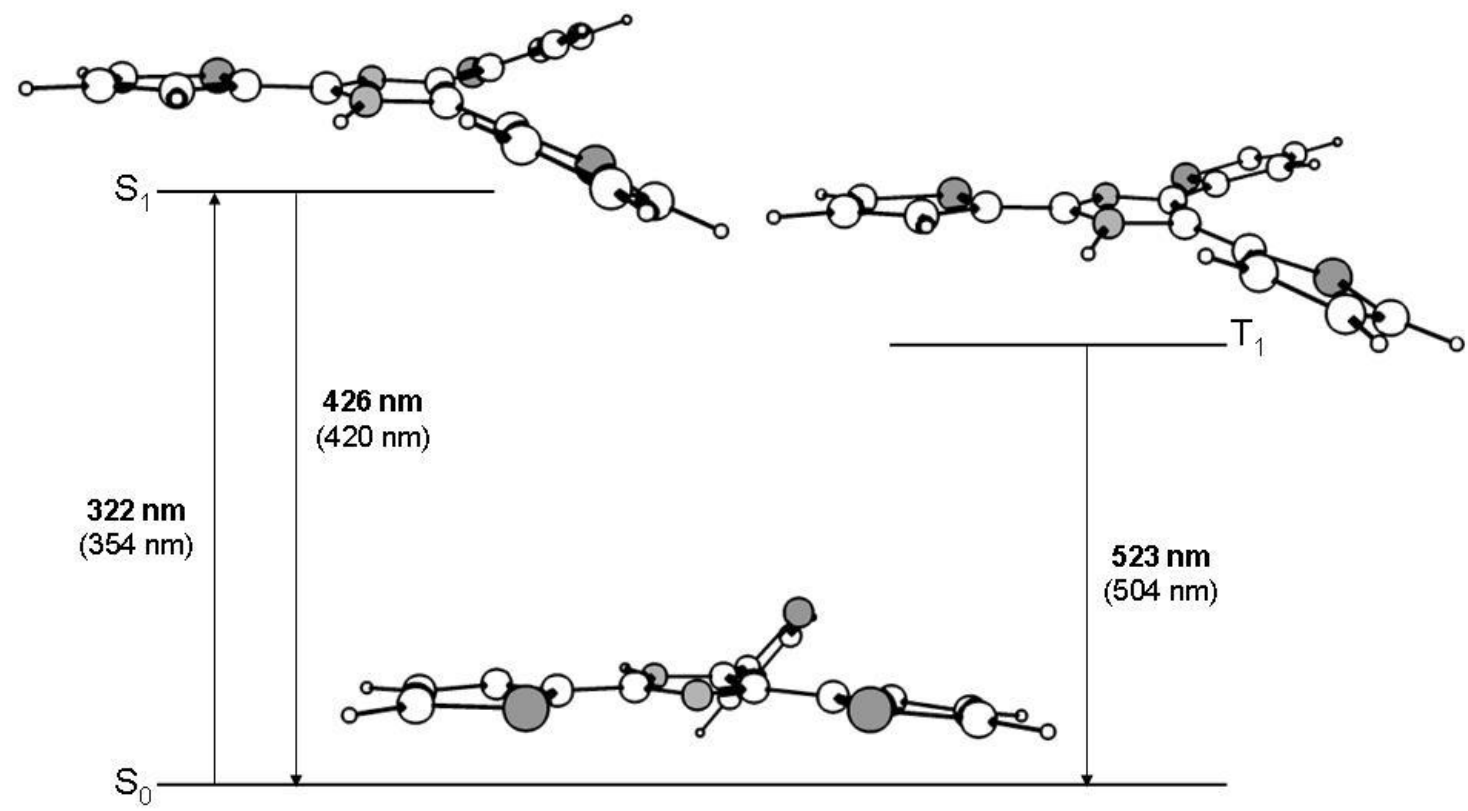


Scheme 1

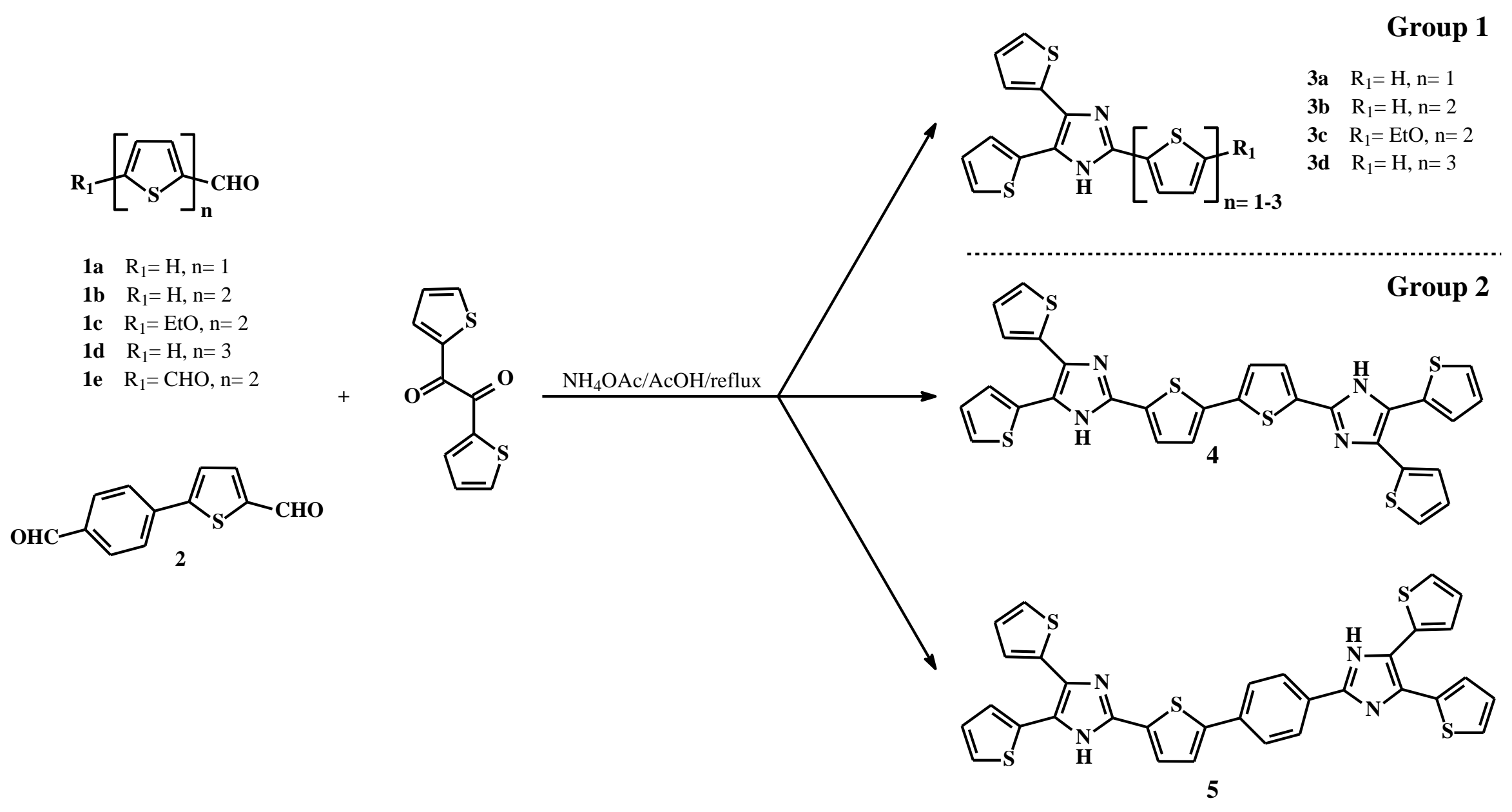




\section{References and Notes}

(1) Costa, T.; Pina, J.; Seixas de Melo, J. Photophysical processes in polymers and oligomers. In Special Periodic Reports in Photochemistry; Albini, A., Ed.; Royal Society of Chemistry: London, 2009; Vol. 37; pp 44.

(2) Hung, L. S.; Chen, C. H. Mater. Sci. Eng. R-Rep. 2002 39, 143.

(3) He, G. S.; Tan, L. S.; Zheng, Q.; Prasad, P. N. Chem. Rev. 2008 108, 1245.

(4) Mishra, A.; Ma, C. Q.; Bauerle, P. Chem. Rev. 2009 109, 1141.

(5) Moylan, C. R.; Miller, R. D.; Twieg, R. J.; Betterton, K. M.; Lee, V. Y.; Matray, T. J.; Nguyen, C. Chem. Mat. 1993 5, 1499.

(6) Bu, X. R.; Li, H. Y.; VanDerveer, D.; Mintz, E. A. Tetrahedron Lett. 1996 37, 7331.

(7) Santos, J.; Mintz, E. A.; Zehnder, O.; Bosshard, C.; Bu, X. R.; Gunter, P. Tetrahedron Lett. 2001 42, 805.

(8) Wang, S.; Zhao, L.; Xu, Z.; Wu, C.; Cheng, S. Mater. Letters 2002 56, 1035.

(9) Wu, W.; Ye, C.; Wang, D. Arkivoc 2003, 59.

(10) Wu, W.; Zhang, Z.; Zhang, X. J. Chem. Res. $20042004,617$.

(11) Feng, K.; De Boni, L.; Misoguti, L.; Mendonca, C. R.; Meador, M.; Hsu, F. L.; Bu, X. R. Chem. Commun. 2004, 1178.

(12) Feng, K.; Hsu, F. L.; Van DerVeer, D.; Bota, K.; Bu, X. R. J. Photochem. Photobiol. A-Chem. 2004 165, 223.

(13) Wu, W.; Zhang, Z. L.; Zhang, X. Y. J. Nonlinear Opt. Phys. Mater. 2005 14, 61.

(14) Feng, K.; Hsu, F. L.; Bota, K.; Bu, X. R. Microchem J. 2005 81, 23.

(15) Zhao, L.; Li, S. B.; Wen, G. A.; Peng, B.; Huang, W. Mater. Chem. Phys. 2006 100,460 .

(16) Zhang, M.; Li, M.; Zhao, Q.; Li, F.; Zhang, D.; Zhang, J.; Yi, T.; Huang, C. Tetrahedron Lett. 2007 48, 2329.

(17) Pan, Y.; Tang, X. Z.; Zhu, L.; Huang, Y. W. Eur. Polym. J. 2007 43, 1091.

(18) Ren, J.; Wang, S. M.; Wu, L. F.; Xu, Z. X.; Dong, B. H. Dyes Pigment. 2008 76, 310.

(19) Pan, W. L.; Tan, H. B.; Chen, Y.; Mu, D. H.; Lin, H. B.; Wan, Y. Q.; Song, H. C. Dyes Pigment. 2008 76, 17.

(20) Zhang, M.; Li, M. Y.; Li, F. Y.; Cheng, Y. F.; Zhang, J. P.; Yi, T.; Huang, C. H. Dyes Pigment. 2008 77, 408.

(21) Pan, Y.; Tang, X. Z. Eur. Polym. J. 2008 44, 408.

(22) Fang, Z.; Wang, S.; Zhao, L.; Xu, Z.; Ren, J.; Wang, X.; Yang, Q. Materials Chemistry and Physics 2008 107, 305.

(23) Pan, Y.; Tang, X. Z. J. Appl. Polym. Sci. 2008 108, 2802.

(24) Fichou, D. Handbook of Oligo- and Polythiophenes Wiley-VCH, Weinhem, 1999.

(25) Silcoff, E. R.; Sheradsky, T. Macromolecules 1998 31, 9116.

(26) Burrows, H. D.; Seixas de Melo, J.; Serpa, C.; Arnaut, L. G.; Monkman, A. P.; Hamblett, I.; Navaratnam, S. J. Chem. Phys. 2001 115, 9601.

(27) Dufresne, S.; Hanan, G. S.; Skene, W. G. J. Phys. Chem. B 2007 111, 11407.

(28) Bellina, F.; Cauteruccio, S.; Rossi, R. Tetrahedron 2007 63, 4571.

(29) Batista, R. M. F.; Costa, S. P. G.; Belsley, M.; Lodeiro, C.; Raposo, M. M. M. Tetrahedron 2008 64, 9230.

(30) Batista, R. M. F.; Costa, S. P. G.; Belsley, M.; Raposo, M. M. M. Dyes Pigment. $200980,329$. 
(31) Lozinskaya, N. A.; Tsybezova, V. V.; Proskurnina, M. V.; Zefirov, N. S. Russ. Chem. Bull. 2003 52, 674.

(32) Chou, C. H.; Chu, L. T.; Chiu, S. J.; Lee, C. F.; She, Y. T. Tetrahedron 2004 60, 6581 .

(33) Becker, R. S.; Seixas de Melo, J.; Maçanita, A. L.; Elisei, F. J. Phys. Chem. 1996 100, 18683.

(34) Pina, J.; Burrows, H. D.; Becker, R. S.; Dias, F. B.; Maçanita, A. L.; Seixas de Melo, J. J. Phys. Chem. B 2006 110, 6499.

(35) Pina, J.; Seixas de Melo, J.; Burrows, H. D.; Maçanita, A. L.; Galbrecht, F.; Bunnagel, T.; Scherf, U. Macromolecules 2009 42, 1710.

(36) Striker, G.; Subramaniam, V.; Seidel, C. A. M.; Volkmer, A. J. Phys. Chem. B $1999103,8612$.

(37) Pina, J.; Seixas de Melo, J.; Burrows, H. D.; Bilge, A.; Farrell, T.; Forster, M.; Scherf, U. J. Phys. Chem. B 2006 110, 15100.

(38) Bensasson, R. V.; Land, E. J.; Truscott, T. G. Excited states and free radicals in biology and medicine; Oxford Science Publications, Oxford, 1993.

(39) Murov, S.; Carmichael, I.; Hug, G. L. Handbook of Photochemistry; Marcel and Dekker Inc., New York, 1993.

(40) Frisch, M. J.; Trucks, G. W.; Schlegel, H. B.; Scuseria, G. E.; Robb, M. A.; Cheeseman, J. R.; Montgomery, J., J. A.; Vreven, T.; Kudin, K. N.; Burant, J. C.; Millam, J. M.; Iyengar, S. S.; Tomasi, J.; Barone, V.; Mennucci, B.; Cossi, M.; Scalmani, G.; Rega, N.; Petersson, G. A.; Nakatsuji, H.; Hada, M.; Ehara, M.; Toyota, K.; Fukuda, R.; Hasegawa, J.; Ishida, M.; Nakajima, T.; Honda, Y.; Kitao, O.; Nakai, H.; Klene, M.; Li, X.; Knox, J. E.; Hratchian, H. P.; Cross, J. B.; Bakken, V.; Adamo, C.; Jaramillo, J.; Gomperts, R.; Stratmann, R. E.; Yazyev, O.; Austin, A. J.; Cammi, R.; Pomelli, C.; Ochterski, J. W.; Ayala, P. Y.; Morokuma, K.; Voth, G. A.; Salvador, P.; Dannenberg, J. J.; Zakrzewski, V. G.; Dapprich, S.; Daniels, A. D.; Strain, M. C.; Farkas, O.; Malick, D. K.; Rabuck, A. D.; Raghavachari, K.; Foresman, J. B.; Ortiz, J. V.; Cui, Q.; Baboul, A. G.; Clifford, S.; Cioslowski, J.; Stefanov, B. B.; Liu, G.; Liashenko, A.; Piskorz, P.; Komaromi, I.; Martin, R. L.; Fox, D. J.; Keith, T.; AlLaham, M. A.; Peng, C. Y.; Nanayakkara, A.; Challacombe, M.; Gill, P. M. W.; Johnson, B.; Chen, W.; Wong, M. W.; Gonzalez, C.; Pople, J. A. Gaussian 03, Revision C.02; Gaussian, Inc.: Wallingford CT, 2004.

(41) Becke, A. D. J. Chem. Phys. 1993 98, 1372.

(42) Francl, M. M.; Pietro, W. J.; Hehre, W. J.; Binkley, J. S.; Gordon, M. S.; Defrees, D. J.; Pople, J. A. J. Chem. Phys. 1982 77, 3654.

(43) Woon, D. E.; Dunning, T. H. J. Chem. Phys. 1993 98, 1358.

(44) Runge, E.; Gross, E. K. U. Phys. Rev. Lett. 1984 52, 997.

(45) Kendall, R. A.; Dunning, T. H.; Harrison, R. J. J. Chem. Phys. 1992 96, 6796.

(46) Foresman, J. B.; Headgordon, M.; Pople, J. A.; Frisch, M. J. J. Phys. Chem. 1992 96, 135.

(47) Portmann, S.; Luthi, H. P. Chimia 2000 54, 766.

(48) Davidson, D.; Weiss, M.; Jelling, M. J. Org. Chem. 1937 2, 319.

(49) Raposo, M. M. M.; Kirsch, G. Tetrahedron 2003 59, 4891.

(50) Costa, S. P. G.; Batista, R. M. F.; Raposo, M. M. M. Tetrahedron 2008 64, 9733.

(51) Costa, S. P. G.; Batista, R. M. F.; Cardoso, P.; Belsley, M.; Raposo, M. M. M. Eur. J. Org. Chem. 2006, 3938. 
(52) Seixas de Melo, J.; Pina, J.; Burrows, H. D.; Brocke, S.; Herzog, O.; Thorn-Csanyi, E. Chem. Phys. Lett. 2004 388, 236.

(53) Wasserberg, D.; Marsal, P.; Meskers, S. C. J.; Janssen, R. A. J.; Beljonne, D. J. Phys. Chem. B 2005 109, 4410.

(54) Rentsch, S.; Yang, J. P.; Paa, W.; Birckner, E.; Schiedt, J.; Weinkauf, R. PhysChemChemPhys 1999 1, 1707.

(55) Rothe, C.; Hintschich, S.; Monkman, A. P.; Svensson, M.; Anderson, M. R. J. Chem. Phys. 2002 116, 10503.

(56) Martinez, C. G.; Neumer, A.; Marti, C.; Nonell, S.; Braun, A. M.; Oliveros, E. Helv. Chim. Acta 2003 86, 384.

(57) Fabian, J. Theor. Chem. Acc. 2001 106, 199.

(58) Fabian, J.; Diaz, L. A.; Seifert, G.; Niehaus, T. Theochem-J. Mol. Struct. 2002 $594,41$.

(59) Jamorski, C.; Foresman, J. B.; Thilgen, C.; Luthi, H. P. J. Chem. Phys. 2002 116, 8761.

(60) Milian, B.; Orti, E.; Hernandez, V.; Navarrete, J. T. L.; Otsubo, T. J. Phys. Chem. B 2003 107, 12175.

(61) Pogantsch, A.; Heimel, G.; Zojer, E. J. Chem. Phys. 2002 117, 5921.

(62) Pina, J.; Seixas de Melo, J. S.; Burrows, H. D.; Batista, R. M. F.; Costa, S. P. G.; Raposo, M. M. M. J. Phys. Chem. A 2007 111, 8574. 